\title{
The Impact of Nurse Understaffing on the Transmission of Hepatitis C Virus in a Hospital-Based Hemodialysis Unit
}

\author{
Anil Kumar Saxena ${ }^{a}$ B.R. Panhotra ${ }^{b}$ \\ Departments of a Nephrology and b Microbiology and Infection Control, King Fahad Hospital and \\ Tertiary Care Center, Hofuf, Saudi Arabia
}

\section{Key Words}

Nurse understaffing $\cdot$ Hemodialysis $\cdot$ Hepatitis $C$ virus · Nosocomial transmission

\begin{abstract}
Objective: To determine the impact of nurse understaffing on the transmission of hepatitis $C$ virus (HCV) infection in a large hospital-based hemodialysis (HD) unit with a high HCV prevalence. Subjects and Methods: The records of 198 patients (107 males and 91 females) with end-stage renal disease enrolled on long-term HD at King Fahad Hospital and Tertiary Care Center, Hofuf, Saudi Arabia, from August 1995 to August 2000, were retrospectively reviewed. The patients were assigned to HD groups of varying patient-to-nurse (P/N) ratios: group I, 2:1; group II, 3:1, and group III, 4:1. HCV prevalence, seroconversion rates, history of blood transfusion and dialysis age (time span since the initiation of the HD treatment) were recorded and compared. Results: The overall HCV prevalence and seroconversion rate per year were 43.4 and $8.6 \%$, respectively. Group I had the lowest $\mathrm{HCV}$ prevalence and annual seroconversion rate $(26.8 \%$; $5.3 \%)$, followed by group II (43.6\%; $8.7 \%)$; group III had the highest $\mathrm{HCV}$ prevalence and seroconversion rate (71.8\%; 14.4\%). Anti-HCV positivity was associated with
\end{abstract}

\section{KARGER}

Fax +41613061234

E-Mail karger@karger.ch

www. karger.com
(C) 2004 S. Karger AG, Basel

1011-7571/04/0133-0129\$21.00/0

Accessible online at:

www. karger.com/mpp a higher dialysis age. Conclusion: The finding that the patients in the groups with the relatively higher $\mathrm{P} / \mathrm{N}$ ratio had the significantly higher HCV prevalence and seroconversion rates per year indicates that understaffing is likely to play a major role in the transmission of HCV in HD units, and we suggest that improved staffing may be helpful in reducing the HCV transmission in such dialysis units.

Copyright $@ 2004$ S. Karger AG, Base

\section{Introduction}

Hepatitis C (HCV) infection, widespread on a global scale, has become a major cause of morbidity and mortality in patients on long-term hemodialysis (HD), including those in Middle Eastern countries [1-3]. The growing burden of HCV infection for immunocompromised patients on HD is of particular concern due to the increased risk of chronic liver disease, complications in renal transplantation and death - along with the enormously high cost of the management of end-stage renal disease (ESRD) [3].

Nosocomial infection has been reported to be the principal mode of HCV transmission in modern hospitalbased settings [4]. The compelling requirement for a vascular access site, along with the extracorporeal circulation 
necessary to perform $\mathrm{HD}$, adds to the risk of parenteral exposure to prevailing HCV infection within the unit. Nurse understaffing in units with high HCV prevalence may further increase the odds of HCV transmission since insufficient time to fully comply with disinfection requirements may facilitate cross-infection via blood-contaminated gloves and hands, dialysis equipment, dialyzer and blood line surfaces [4-9].

This study was designed to investigate any impact that nurse understaffing might have on the transmission of $\mathrm{HCV}$ in an HD unit.

\section{Subjects and Methods}

\section{Study Population}

In this retrospective analysis, records of 198 ESRD patients enrolled for long-term HD from August 2, 1995, to August 1, 2000, at King Fahad Hospital and Tertiary Care Center, Hofuf, Saudi Arabia, were reviewed. There were 107 males and 91 females. The mean age of the patients was $47.0 \pm 17.5$ years (range 15-84 years). Age, gender and HCV serostatus, units of blood transfused, length of time on $\mathrm{HD}$ (dialysis age) and the number of patients cared for by $1 \mathrm{HD}$ nurse were collected.

The subjects were assigned to 1 of 3 groups of varying patient/ nurse $(\mathrm{P} / \mathrm{N})$ ratios: group I, 2:1 $(\mathrm{n}=56)$; group II, 3:1 $(\mathrm{n}=110)$, or group III, 4:1 $(n=32)$. These ratios were affected by nurse turnover and patient comorbidities (ischemic heart disease, diabetes mellitus and congestive heart failure) that involved higher levels of nursing care during HD. Additionally, age, gender, nursing hours, patientdays, number of units of blood transfused and dialysis age, along with HCV seroprevalence and seroconversion rates, were noted in each of these groups and matched.

These ESRD patients were dialyzed 2 or 3 times per week for $4 \mathrm{~h}$ each time using disposable single-use, high-flux dialyzer membranes (polysulfone, Bellco, Mirandola, Italy; polyacrylonitrile Filtrat 10 AN 69, Hospal, Meyzieu, France) and blood lines. HCV-positive and -negative patients were dialyzed in a common area, while patients with HBV infection were strictly isolated as per Centers for Disease Control (CDC) guidelines [10]. Male and female patients were placed in separate rooms.

\section{HD Nurse Staffing}

HD staff nurses were assigned randomly, regardless of HCV serological status, with the same staff nurse taking care of HCV-positive and HCV-negative patients but with strict enforcement of universal infection control precautions. The $\mathrm{P} / \mathrm{N}$ ratio was based on the number of dialysis nurses and patients. Technicians engaged solely to manage and repair the dialysis machines were not counted as nursing staff as they were not directly involved in the HD patients' care.

\section{Infection Control Precautions}

Strict adherence to universal precautions for infection control as recommended by the CDC was practiced routinely, regardless of HCV or HBV serological status [10,11]. All staff members taking care of HD patients wore gowns, masks, gloves and protective eye wear while preparing, performing and terminating dialysis. Gloves were changed after each patient manipulation, and hands were washed between each patient. Meticulous cleaning and disinfection of environmental surfaces at each dialysis station was done before all dialysis sessions, and wastes generated were disposed of in an incinerator, in accordance with Saudi Arabia regulations governing medical waste.

\section{Disinfection of HD Machines}

The HD machines (Hospal Integra ${ }^{\mathrm{TM}}$, Meyzieu, France), were disinfected after each patient (HCV positive or negative) with hot water and chemicals (Puristeril and sodium hypochlorite). Chemical disinfection, as per instructions of the manufacturers, involved using $0.1 \%$ peracetic acid (Puristeril ${ }^{\circledR} 340$, Fresenius AG, Homburg, Germany) and running the machine at $85^{\circ} \mathrm{C}$ for $35 \mathrm{~min}$ after each dialysis session. After the chemical disinfection, hot water, at $80-90^{\circ} \mathrm{C}$, was run at a high flow rate for $60 \mathrm{~min}$. This procedure was performed at the end of the day on every machine in preparation for the next day's work, while disinfection of the dialysate circuit was performed with sodium hypochlorite $(<0.3 \mathrm{ppm})$ after each individual session. External, disposable venous and arterial pressure transducer filters were also changed and discarded between each patient treatment after single use.

\section{Detection of HCV Infection}

Blood samples were collected from all patients on the date of their enrollment in the unit and subsequently every 3 months for analysis of $\mathrm{HCV}$ infection. The serum samples were stored at $-20^{\circ} \mathrm{C}$ until analysis for anti-HCV antibodies by a second-generation enzymelinked immunosorbent assay (ELISA-2) using Murex version III kits (Murex Biotech Ltd., Dartford, UK) was done. All the anti-HCVpositive samples were confirmed by a recombinant immunoblot assay (Chiron-RIBA-HCV 3.0, Ortho Clinical Diagnostics, Raritan, N.J., USA). Seroconversion rates were calculated at the end of each year by recording the percentage of new cases per year.

In addition to patients, all personnel (renal physicians, staff nurses and HD technicians) were tested annually for anti-HCV/HBV and liver enzymes. Blood and blood products used for transfusion were acquired from voluntary donors and screened for anti-HCV with ELISA-2.

\section{Statistical Analyses}

The statistical package for social sciences SPSS version 10.1 (SPSS, Chicago, Ill., USA) was used for data processing. The value $\mathrm{p}<0.05$ (two-sided) was used as a cutoff level for statistical significance. The $\chi^{2}$ test was used to assess the difference between two proportions of anti-HCV-positive patient groups with different N/P ratios. The Student $t$ test was used to compare between the means of two quantitative variables. Mantel-Haenszel odds ratios and 95\% confidence intervals were used to investigate the association between the seroconversion rates and selected risk factors. Significantly associated variables with the risk of acquiring HCV infection in the univariate analysis were excluded in a multivariate logistic regression model.

Since the duration of follow-up was not uniform, the prognostic significance of being dialyzed with different $\mathrm{P} / \mathrm{N}$ ratios was tested by cumulative survival analysis at the main time points [HCV serology at the beginning of HD (the study entry) and the time of becoming anti-HCV positive]. The cumulative survival curves were obtained by the Kaplan-Meier survival method. The equality of the survival curves was assessed by the Cox proportional hazard test. 
Table 1. Determinants of HCV seroconversion in 198 HD patients

\begin{tabular}{|c|c|c|c|c|}
\hline \multirow[t]{2}{*}{ Variables } & \multicolumn{2}{|c|}{ Anti-HCV serology } & \multirow{2}{*}{$\begin{array}{l}\text { Mean sero- } \\
\text { conversions/year }\end{array}$} & \multirow[t]{2}{*}{$\mathrm{p}$ value } \\
\hline & positive & negative & & \\
\hline Patients & $86 / 198(43.4)$ & $112 / 198(56.6)$ & $17.2(8.6)$ & \\
\hline Mean age $\pm S D$, years & $65.0 \pm 9.2$ & $49.0 \pm 5.8$ & & 0.028 \\
\hline \multicolumn{5}{|l|}{ Gender } \\
\hline Male & $54 / 86(62.8)$ & $53 / 112(47.3)$ & $10.8(10.09)$ & 0.043 \\
\hline Female & $32 / 86(37.2)$ & $59 / 112(52.6)$ & $6.4(7.03)$ & \\
\hline Mean dialysis age $\pm \mathrm{SD}$, months & $50.0 \pm 8.6$ & $29.0 \pm 5.9$ & & 0.002 \\
\hline Mean number \pm SD of units of blood transfused & $7.2 \pm 2.5$ & $6.8 \pm 3.7$ & & NS \\
\hline \multicolumn{5}{|l|}{$\mathrm{P} / \mathrm{N}$ ratio } \\
\hline Group I (2:1) & $15 / 56(26.8)$ & $41 / 56(73.2)$ & $3.0(5.35)$ & reference group ${ }^{1}$ \\
\hline Group II (3:1) & $48 / 110(43.8)$ & $62 / 110(54.4)$ & $9.6(8.7)$ & $<0.05$ \\
\hline Group III $(4: 1)$ & $23 / 32(71.8)$ & $9 / 32(14.4)$ & $4.6(14.4)$ & $<0.001$ \\
\hline
\end{tabular}

Results in parentheses indicate percentages. Dialysis age = Time span since the initiation of the HD treatment; SD = standard deviation; $\mathrm{NS}=$ not significant $; \mathrm{P} / \mathrm{N}=$ patient-to-nurse ratio.

1 Odds ratio $=1$.

\section{Results}

All ESRD patients had been on HD for a mean of 39.5 \pm 7.25 months (range 4-102 months).

Factors affecting $\mathrm{HCV}$ positivity are listed in table 1. Of 198 ESRD patients, 86 (43.4\%), including 54 males and 32 females, were anti-HCV positive. They were older $(65.0 \pm$ 9.2 years) than anti-HCV-negative patients $(49.0 \pm 5.8$ years). The difference in age was statistically significant $(\mathrm{p}<0.03)$. More males $(62.8 \%, 54 / 86)$ than females $(37.2 \%$, $32 / 86)$ were $\mathrm{HCV}$ positive, and the difference was statistically significant $(p<0.043)$. The number of units of blood transfused to $\mathrm{HCV}$-positive and -negative patients was the same: $7.2 \pm 2.5$ and $6.8 \pm 3.7$ units, respectively.

Anti-HCV-positive patients had a higher dialysis age (50.0 \pm 8.6 months) than anti-HCV-negative patients $(29.0 \pm 5.9$ months). The difference was statistically significant $(\mathrm{p}<0.02)$. The overall $\mathrm{HCV}$ seroconversion rate was $8.6 \%$ per year (table 1). The mean HCV seroprevalence and seroconversion rates for the 3 groups and the yearly seroconversion rates are shown in figures 1 and 2 , respectively. Among different patient groups, group I $(\mathrm{P} / \mathrm{N}$ ratio $2: 1)$ had the lowest $\mathrm{HCV}$ prevalence $(26.8 \%$, $15 / 56)$ and yearly seroconversion rate (5.3\%), at a mean dialysis age of $68.0 \pm 9.2$ months. Higher HCV prevalence $(43.6 \%, 48 / 110)$ and yearly seroconversion $(8.7 \%)$ rates were found in group II (P/N ratio 3:1), with a mean dialysis age of $47.0 \pm 9.4$ months. Group III $(\mathrm{P} / \mathrm{N}$ ratio 4:1) had the highest HCV prevalence $(71.8 \%, 23 / 32)$ and

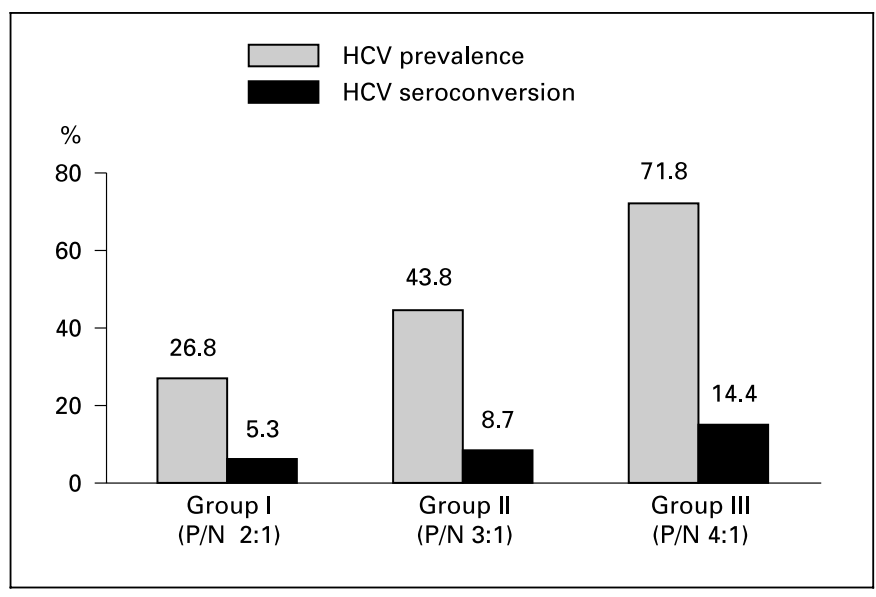

Fig. 1. Mean HCV seroprevalence and mean seroconversion rates among various groups with different $\mathrm{P} / \mathrm{N}$ ratios.

seroconversions (14.4\%) per year, at a mean dialysis age of $35.0 \pm 2.4$ months. As should be expected, group I had the highest number of nursing hours per patient-day (48) while groups II and III had 23.6 and $24 \mathrm{~h}$, respectively.

The other factors analyzed, mean age, male/female ratio and units of blood transfused, were comparable among all the 3 groups (table 2).

According to the criteria expressed in Patients and Methods, 2 of the 4 variables included in the multiple logistic regression equation (dialysis age and staffing levels) 
Fig. 2. Annual HCV seroconversion rates among various groups with different $\mathrm{P} / \mathrm{N}$ ratios during the study period (1995-2000).
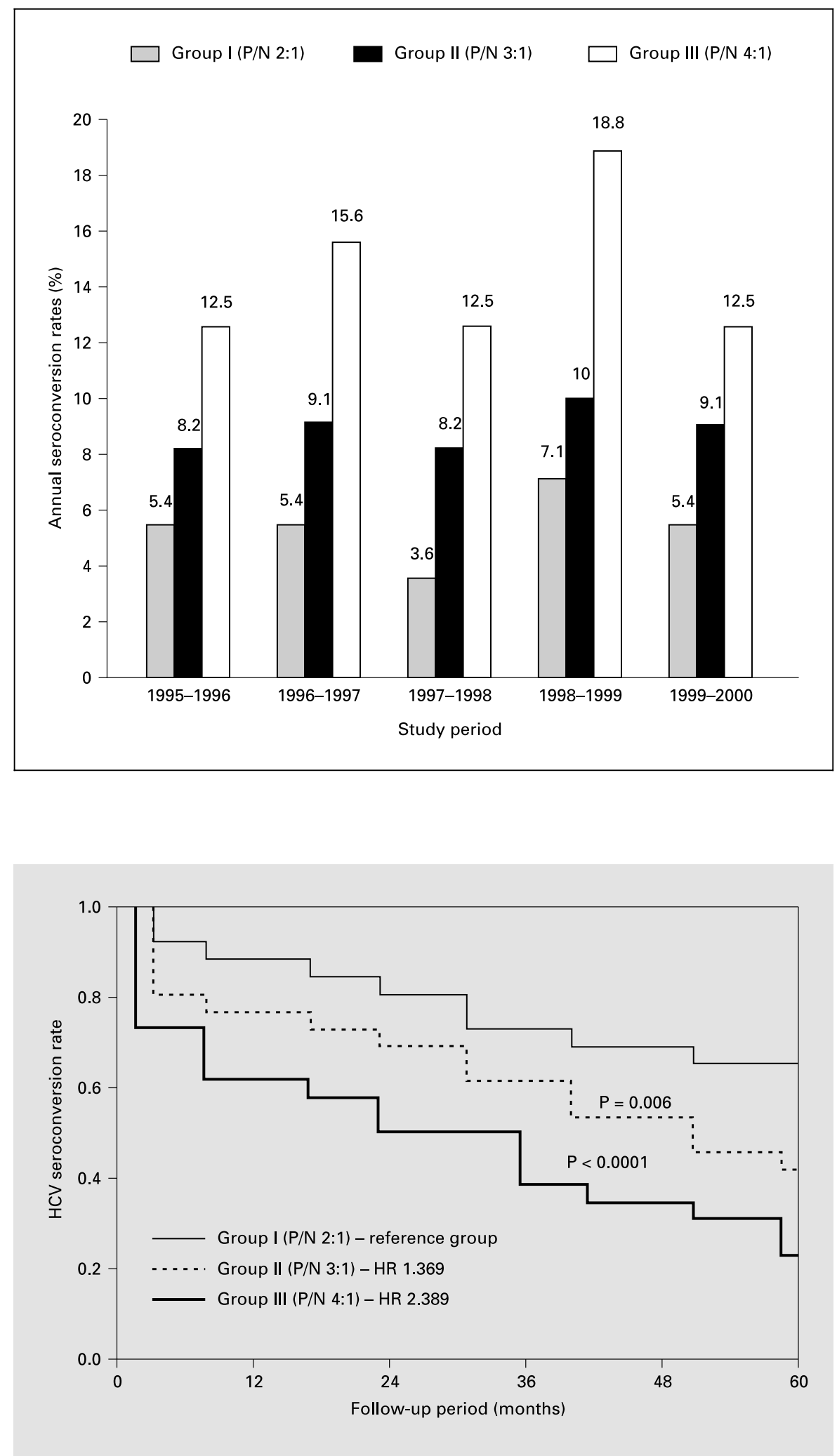

Fig. 3. Kaplan-Meier cumulative survival curves demonstrating the probability of $\mathrm{HCV}$ seroconversions in various patient groups being dialyzed with different staffing levels. $\mathrm{HR}=$ Hazard ratio; $95 \% \mathrm{CI}=95 \%$ confidence interval. 
Table 2. Patient characteristics and determinants of $\mathrm{HCV}$ seroconversion among various patient groups dialyzed with different $\mathrm{P} / \mathrm{N}$ ratios (1995-2000)

\begin{tabular}{|c|c|c|c|}
\hline Variables & $\begin{array}{l}\text { Group I } \\
\text { (P/N ratio 2:1) }\end{array}$ & $\begin{array}{l}\text { Group II } \\
\text { (P/N ratio 3:1) }\end{array}$ & $\begin{array}{l}\text { Group III } \\
\text { (P/N ratio 4:1) }\end{array}$ \\
\hline Patients & $56 / 198(28.3)$ & $110 / 198(55.5)$ & $32 / 198(16.2)$ \\
\hline Mean age $\pm \mathrm{SD}$, years & $63.8 \pm 5.8$ & $59.2 \pm 8.2$ & $50.0 \pm 9$ \\
\hline \multicolumn{4}{|l|}{ Gender } \\
\hline Male & $36 / 56(64.3)$ & $54 / 110(49.1)$ & $17 / 32(53.2)$ \\
\hline Female & $20 / 56(35.7)$ & $56 / 110(50.9)$ & $15 / 32(46.8)$ \\
\hline Nursing hours & 322,560 & 311,040 & 92,160 \\
\hline Patient-days & 6,720 & 13,200 & 3,840 \\
\hline Nursing hours per patient-day & 48 & 23.56 & 24 \\
\hline Mean number $\pm \mathrm{SD}$ of units of blood transfused & $7.5 \pm 2.5$ & $6.9 \pm 2.6$ & $7.2 \pm 2.4$ \\
\hline Mean dialysis age $\pm \mathrm{SD}$, months & $68.0 \pm 9.2$ & $47.0 \pm 9.4$ & $35 \pm 7.3$ \\
\hline \multicolumn{4}{|l|}{$\mathrm{HCV}$ serology } \\
\hline Positive & $15 / 56(26.8)$ & $48 / 110(43.8)$ & $23 / 32(71.8)$ \\
\hline Negative & $41 / 56(73.2)$ & $62 / 110(56.4)$ & $9 / 32(28.2)$ \\
\hline Mean seroconversions/year & $3(5.35)$ & $9.6(8.7)$ & $4.6(14.4)$ \\
\hline OR, $95 \% \mathrm{CI}, \mathrm{p}$ value & reference group ${ }^{1}$ & $2.11,0.99-4.50,<0.05$ & $6.98,2.39-20.93,<0.001$ \\
\hline
\end{tabular}

Figures in parentheses indicate percentages. Dialysis age $=$ Time span since the initiation of the HD treatment; OR = odds ratio; $95 \% \mathrm{CI}=$ $95 \%$ confidence interval; $\mathrm{SD}=$ standard deviation; nursing hours = total nursing hours during study period; patient-days = total patient hours on HD during study period divided by $24 \mathrm{~h}$.

$1 \quad \mathrm{OR}=1$.

remained in the multiple logistic regression model. The other 2 variables (age and male gender) did not reach statistical significance and were excluded. The 2 factors that showed a statistically significant association in univariate analysis maintained their effect after adjustment of remaining potential confounders. Kaplan-Meier survival curves were drawn showing a relationship between the HCV seroconversions among patient groups with different staffing ratios $(2: 1,3: 1$ and $4: 1)$ and the follow-up time period expressed in months.

Survival data with a Cox regression model and estimation of hazard ratios for the 3 patient groups are shown in figure 3 .

No HD personnel tested positive for $\mathrm{HCV} / \mathrm{HBV}$ at any stage in the study.

\section{Discussion}

The HCV seroprevalence of $43.4 \%$ observed in this study is comparable to the $43.2 \%$ reported in the Al-Hasa region of Saudi Arabia [12]. However, it is much lower than the $68 \%$ reported in a multicenter epidemiological study also carried out on HD patients in Saudi Arabia [1]. The overall seroconversion rate of 8.6 per year observed
Table 3. Determinants of the HCV seroconversion by multivariate analysis (1995-2000)

\begin{tabular}{lll}
\hline Determinants & MLR OR & $95 \%$ CI \\
\hline $\begin{array}{l}\text { Dialysis age } \\
\text { Staffing levels }\end{array} \quad 4.3$ & $1.383-15.541$ \\
$\quad$ Group I (P/N 2:1) & 1 & reference group \\
$\quad$ Group II (P/N 3:1) & 5.9 & $1.863-17.836$ \\
$\quad$ Group III (P/N 4:1) & 9.8 & $2.663-32.924$ \\
\hline
\end{tabular}

Dialysis age $=$ Time span (months) since the initiation of the HD treatment; MLR OR (multiple logistic regression odds ratios) and $95 \%$ CI (95\% confidence Intervals) were adjusted for the variables having $\mathrm{p}<0.05$ and/or odds ratios $\geq 2$ (i.e. age, male gender, dialysis age, staffing levels) at univariate analysis of anti-HCV-positive patients among various patient groups on HD with different staffing levels, as shown in table 1 .

1 Odds ratio $=1$.

at this tertiary care center is comparable to those of 7-9\% reported from other centers of Saudi Arabia and elsewhere $[1,6]$. However, annual seroconversion rates of $>5 \%$ reported in high-prevalence HD units ( $>20 \%$ prevalence rates) remain a cause for concern [6]. 
One plausible explanation for the high seroconversion rate is nurse understaffing, as manifested in the number of patients per HD group. As evidenced in this study, the highest seroconversion rate and $\mathrm{HCV}$ prevalence were observed in group III with the highest $\mathrm{P} / \mathrm{N}$ ratio and consequently low nursing hours per patient-day $(24 \mathrm{~h})$. These findings are similar to those reported previously [16-18], which claimed that nurse understaffing increased the risk of nosocomial infection. However, the significant difference in the $\mathrm{HCV}$ prevalence and seroconversion rates between group II (P/N 3:1) and group III (P/N 4:1) in spite of the comparable total nursing hours per patient-day $(23.56$ vs. $24 \mathrm{~h})$ points to the fact that the $\mathrm{P} / \mathrm{N}$ ratio is definitely a much better indicator of the staffing levels in the HD units than the total nursing hours per patientday.

In spite of a policy requiring strict adherence to CDC infection control regulations [11], it is possible - also in cases of understaffing, especially when emergencies arise - that there may be some laxity in adherence due to time constraints or exhaustion. As a result, patients are at increased risk for cross-contamination and consequent nosocomial infection. For example, one study reported failure to change gloves between patients while performing HD treatments, especially during emergency situations [7], and another found HCV-RNA in hand washings from nurses dialyzing $\mathrm{HCV}$-positive and -negative patients [9]. Molecular virological studies have also clearly implicated nosocomial transmission of $\mathrm{HCV}$ within highrisk HD settings [5-9]. Certainly, cross-infection via a nosocomial pathway from already infected patients could occur due to contamination of vascular access sites that necessitate regular punctures and cannulations to carry out HD.

Dialysis age (length of time on HD) has been considered a powerful predictor of $\mathrm{HCV}$ infection risk: the chances of acquiring $\mathrm{HCV}$ infection are much higher after a decade of HD, with a reported predictable risk of $10 \%$ per year [14]. We found a significant association between dialysis age and anti-HCV positivity, consistent with previous findings $[14,15]$. Patients with a dialysis age of 50.0 \pm 8.6 months carried a significantly higher risk $(\mathrm{p}<$ 0.002 ) of acquiring HCV infection than those with a dialysis age of $29.0 \pm 5.9$ months. Shared dialysis equipment and dialyzer reuse have been implicated as factors in patient-to-patient nosocomial HCV transmission since disruption of the membrane integrity while processing the dialyzers could possibly permit the passage of virus into the blood compartment. In addition, lapses in infection control measures, more likely to occur over time, may result in patient-to patient transmission via blood-contaminated machines and the gloves/hands of nursing staff $[1,5-9]$.

However, significantly higher HCV prevalence and seroconversion rates observed in the groups with comparatively lower mean dialysis ages (group II, 47 months, $\mathrm{p}<$ 0.05 , and group III, 35 months, $p<0.001)$ than group I (68 months, $p<0.001$ ) indeed suggest that the acquisition of HCV infection occurs significantly earlier (at a lower dialysis age) among the patients in the groups with higher $\mathrm{P} / \mathrm{N}$ ratios than in those with a relatively lower $\mathrm{P} / \mathrm{N}$ ratio, during the course of long-term dialysis treatment (table 1).

When the odds of HCV seroconversions developing over a 5-year follow-up period were estimated using Kaplan-Meier cumulative survival curves (fig. 3), group I, with the lowest $\mathrm{P} / \mathrm{N}$ ratio $(2: 1)$, had the lowest probability of seroconversions. Although the probability of $\mathrm{HCV}$ seroconversions decreased over time among the 3 patient groups, higher levels of HCV seroconversions were obtained for both groups II and III, with hazard ratios of $1.639(\mathrm{p}<0.006)$ and $2.389(\mathrm{p}<0.0001)$, respectively.

Repeated blood transfusions are no longer considered a major risk factor for the transmission of $\mathrm{HCV}$. Due to routine HCV screening by highly sensitive tests (ELISA anti-HCV) for blood donors, the risk of posttransfusion $\mathrm{HCV}$ infection is currently less than $1 / 100,000$ units [13]. As the numbers of units of blood transfused between the anti-HCV-positive and anti-HCV-negative groups in this study were comparable $(7.2 \pm 2.5$ vs. $6.8 \pm 3.7$ units $)$ and the prevalence of anti-HCV antibody among blood donors in this region is only $0.67 \%$ [12] - significantly lower than the $43.4 \%$ overall $\mathrm{HCV}$ prevalence in this study transmission of $\mathrm{HCV}$ infection within the dialysis unit through means other than blood transfusion is highly probable.

The higher HCV prevalence and annual seroconversion rates seen in the groups with greater numbers of patients per nurse, groups II and III, suggest a breakdown in infection control measures. While strict isolation of $\mathrm{HCV}$-positive patients may be indicated, improving nursing staff levels is likely to play a major role in reducing HCV seroconversion rates, particularly in those HD units where HCV is prevalent [19, 20]. Further studies to clearly define optimal $\mathrm{P} / \mathrm{N}$ ratios for these HD units would also be of great significance. 


\section{Conclusion}

The findings that the patients in the groups with the relatively higher $\mathrm{P} / \mathrm{N}$ ratio had the significantly higher $\mathrm{HCV}$ prevalence and seroconversion rates per year and low nursing hours per patient-day indicate that understaffing is likely to play a major role in the transmission of $\mathrm{HCV}$ in HD units. We therefore suggest that improved staffing will be helpful in reducing the $\mathrm{HCV}$ transmission in such dialysis units.

\section{References}

1 Huraib S, Al Rashed R, Al Drees A, Al Jefry M, Arif $\mathrm{M}$, al-Faleh FA: High prevalence and risk factors for hepatitis C in Saudi Arabia: A need for strategies in dialysis practice. Nephrol Dial Transplant 1995;10:470-474.

2 Hassan AA, Khalil RY: Prevalence of three blood borne viruses (HBV, HCV, HIV-1) among hemodialysis patients in Cairo. Saudi Kidney Dis Transplant Bull 1993;4:72.

3 Espinosa M, Martin-Malo A, Alvarez de Lara MA, Aljama P: Risk of death and liver cirrhosis in anti-HCV positive long-term hemodialysis patients. Nephrol Dial Transplant 2001;16: 1669-1674.

4 McLaughlin KJ, Cameron SO, Good T, McCruden E, Ferguson JC, Davidson F, Simmonds P, Mactier RA, McMillan MA: Nosocomial transmission of hepatitis $\mathrm{C}$ within a British dialysis center. Nephrol Dial Transplant 1997; 12:304-309.

5 Stuyver L, Claeys H, Wyseur A, Van Arnhem W, De Beenhouwer H, Uytendele S, Beckers J, Matthijs D, Leroux-Roels G, Maertens G, De Paepe M: Hepatitis $\mathrm{C}$ virus in hemodialysis unit: Molecular evidence for nosocomial transmission. Kidney Int 1996;49:889-895.

6 Jadoul M: Transmission routes of HCV infection in dialysis. Nephrol Dial Transplant 1996; 11:36-38

7 Okuda K, Hayashi H, Kobayashi S, Irie Y: Mode of hepatitis $\mathrm{C}$ infection transmission not associated with blood transfusion among hemodialysis patients. J Hepatol 1995;23:28-31.
8 Valtuille R, Fernandez JL, Berridi J, Moretto $\mathrm{N}$, del Pino N, Rendo P, Lef L: Evidence of hepatitis $\mathrm{C}$ virus passage across dialysis membrane. Nephron 1998;80:194-195.

9 Alfurayah O, Sabeel A, Al Ahdal MN, Al Meshari K, Kessie G, Hamid M, Dela Cruz DM: Hand contamination with hepatitis $\mathrm{C}$ virus in staff looking after hepatitis $\mathrm{C}$ positive hemodialysis patients. Am J Nephrol 2000;20:103106.

10 CDC Update: Recommendations to prevent hepatitis B virus transmission - United States. MMWR 1995;44:574-575.

11 Centers for Disease Control and Prevention (CDC): Recommendations for preventing transmission of infections among chronic hemodialysis patients. MMWR Recomm Rep 2001;50:1-43

12 Saxena AK, Panhotra BR, Naguib M, Aboras MN, Sundaram DS, Venkateshappa CK, Uzzaman W: Prevalence of hepatitis $\mathrm{C}$ antibodies among hemodialysis patients in Al-Hasa region of Saudi Arabia. Saudi J Kidney Dis Transplant 2001;12:562-565.

13 Van der Poel CL: Hepatitis C virus and blood transfusion: Past and present risks. J Hepatol 1999;31:101-106.

14 Giammaria U, De Meo F, Acetelli S, Tancredi M, Daniele M, Bernabei R, Maschio C: HCV infection in hemodialyzed patients: Incidence and correlation with dialytic age. Nephron 1992;61:335-336.
15 Hardy NM, Sandroni R, Danielson S, Wilson WJ: Antibody to hepatitis $\mathrm{C}$ virus increases with time on hemodialysis. Clin Nephrol 1992; 38:44-48.

16 Fridkin SK, Pear SM, Williamson T H, Galgiani JN, Jarvis WR: The role of understaffing in central venous catheter associated bloodstream infections. Infect Control Hosp Epidemiol 1996;17:150-158.

17 Robert J, Fridkin SK, Blumberg HM, Anderson B, White N, Ray SM, Chan J, Jarvis WR: The influence of composition of the nursing staff on primary blood stream infection rates in surgical intensive care unit. Infect Control Hosp Epidemiol 2000;21:12-17.

18 Petrosillo N, Gilli P, Serraino D, Dentico P, Mele A, Ragni P, Puro V, Casalino C, Ippolito $\mathrm{G}$ : Prevalence of infected patients and understaffing have a role in hepatitis $\mathrm{C}$ transmission in dialysis. Am J Kidney Dis 2001;37:10041010

19 Saxena AK, Panhotra BR: Nosocomial transmission of hepatitis $\mathrm{C}$ virus: Impact of strict isolation on annual seroconversion rate in hemodialysis unit. Saudi J Kidney Dis Transplant 2002;13:186-187.

20 Saxena AK, Panhotra BR, Sundaram DS, Naguib M, Venkateshappa CK, Uzzaman W, Mulhim KA: Impact of dedicated space, dialysis equipment and nursing staff on the transmission of hepatitis $\mathrm{C}$ virus in a hemodialysis unit of the Middle East. Am J Infect Control 2003;31:26-33. 